\title{
MRS-T Launches New Journal, Holds Annual Meeting
}

The Materials Research Society-Taiwan (MRS-T) was founded by a group of scientists dedicated to the advancement and promotion of materials science and technology in Taiwan. To this end, MRS-T publishes technical information about current advances in materials science and technology as well as research and development papers in an MRS-T sponsored journal (Chinese Journal of Materials Science) which is published quarterly in Chinese. MRS-T has recently elected to sponsor an international journal on materials science under the title Materials Physics and Chemistry, published in English by Elsevier. The journal is slated to greet the public this summer.

Each year since its establishment, MRS-T has sponsored an annual spring meeting. This year's meeting was held at National Taiwan University on April 24-26. There were 800 attendees and 400 papers (including oral presentations and posters). The three-day symposium covered all aspects of materials including semiconductors (Si and III-V compounds), superconductors, metals, composites, ceramics, magnetic materials, electronic materials, and optoelectronic materials. Most topics were related to metal materials. The most popular topics were superconductors and diamond film materials.

The highlight of the annual meeting was the presentation of the C.H. Lu Award, established in 1980 in honor of C.H. Lu for his outstanding contribution in the promotion of materials science and technology in Taiwan. Recipients must have an outstanding scientific record, and their work must significantly impact materials research. The recipient of this year's C.H. Lu Award, Professor Chen-Hsien Hwang, has not only achieved advances in bright annealing research, but also in research on automated control for furnace atmospheres and in energy savings for controlled furnace atmospheres.

MRS-T has grown substantially over these years, especially under the guidance of its former presidents Otto C.C. Lin and P.T. Wu. Lin is currently the president of Industrial Technology Research Institute

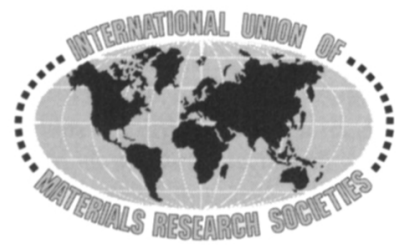

(ITRI). Prior to that, he was the general director of Materials Research Laboratories/ ITRI. Under his leadership, MRL expanded substantially both in facilities and in research results, accelerating the development of materials science in Taiwan and bringing recognition to MRS-T. After serving as MRS-T president, he joined the board of directors of MRS-T. His endeavors on behalf of materials science have made him an honorary member of the Materials Research Society of Japan.
Li-Chung Lee was elected as the new president of MRS-T. Lee received his BS degree from National Taiwan University, and his $\mathrm{PhD}$ from Cornell University. After graduation, Lee worked with Corning Glass for two years and IBM for six years before joining MRL/ITRI. He is now the general director of MRL/ITRI.

MRS-T now has more than 1,800 members; about 1,000 are professors and researchers, while the others are students and business people.

\section{IUMRS - ICAM - 93 Issues Call for Papers}

Papers are being solicited for the IUMRS Third International Conference on Advanced Materials to be held August 31 through September 4, 1993 at Sunshine City, Ikebukuro, Tokyo, Japan.

All invited and contributed papers presented at the conference will be reviewed and published. The official language of the conference is English.

Abstracts (one original and two copies) are due at the ICAM office by January 31, 1993. The text area for each abstract should measure $12 \mathrm{~cm}$ wide by $18 \mathrm{~cm}$ long. Author names, affiliation, business address, telephone and fax numbers should be listed on the abstract outside the text area.

\section{IUMRS - ICAM - 93 Symposia}

A: Composites

B: Glassy Materials

C: Powder Preparation

D: Computer Applications to Materials Science and Engineering (CAMSE '93)

E: Superplastic Phenomena in Ceramics, Intermetallics and Composites

F: Materials Interconnection-Novel Approaches for Interconnection and Joining of Dissimilar Materials

G: Corrosion/Coating of Advanced Materials

$\mathrm{H}$ : Shape Memory Materials

I: Hydrogen Absorbing Materials and Hydride Batteries

J: Structural Ceramics

K: Environmentally Conscious Materials

L: Rare-Earth Iron-Based Permanent Magnet Materials

M: $C_{60}$ and Related Materials

$\mathrm{N}$ : Biomaterials
O: Catalytic Materials

P: Advanced Processing

Q: Ordered Polymers

R: Photo- and Electro-Responsive Materials

S: Electronic Materials and Processing for ULSI

T: Biosensors

U: Materials Synthesis and Modification by Ion Beams and/or Laser Beams

V: Materials for Information Storage Media

W: Fabrication of Silicon-Based Ceramics

$X$ : Frontiers of Materials Science and Engineering

Y: Diamond and Related Materials

Z: Functionally Gradient Materials

AA: Grain and Interphase Boundaries

BB: Nanophase and Nanocomposite Materials

CC: Superlattices and Quantum Microstructures

DD: Surfaces and Interfaces

EE: Construction and Functions of Organic Thin Films

GG:Microgravity and Materials

$\mathrm{HH}$ :Superconducting Materials

II: Ferroelectrics

JJ: Nondestructive Evaluation

KK: Dielectric Materials

Send abstracts and requests for information to:

IUMRS - ICAM - 93

clo The Nikkan Kogyo Shimbun, Ltd.

Business Bureau

1-8-10 Kudan Kita, Chiyoda-ku

Tokyo 102, Japan

Phone (81) 3-3222-7162

Fax (81) 3-3221-7137 